\title{
(6) OPEN ACCESS \\ The Global Comparators project: international comparison of 30-day in-hospital mortality by day of the week
}

\author{
Milagros Ruiz, Alex Bottle, Paul P Aylin
}

- Additional material is published online only. To view please visit the journal online (http://dx.doi.org/10.1136/bmjqs2014-003467).

Dr Foster Unit, PCPH Imperial College London, London, UK

\section{Correspondence to} Dr Milagros Ruiz, Dr Foster Unit, PCPH Imperial College London, 3 Dorset Rise, London EC4Y 8EN, UK; m.ruiz@imperial.ac.uk

Received 8 August 2014 Revised 17 April 2015 Accepted 2 May 2015
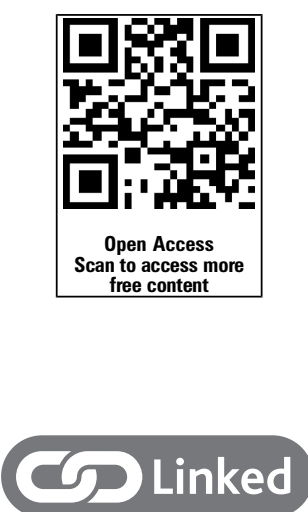

- http://dx.doi.org/10.1136/ bmjqs-2015-004360

CrossMark

To cite: Ruiz M, Bottle $A$ Aylin PP. BMJ Qual Saf 2015;24:492-504.

\begin{abstract}
Objective To examine the association of mortality by day of the week for emergency and elective patients.

Design Retrospective observational study using the international dataset from the Global

Comparators (GC) project consisting of hospital administrative data.
\end{abstract}

Setting 28 hospitals from England, Australia, USA and the Netherlands during 2009-2012.

Participants Emergency and surgical-elective patients.

Main outcome measures In-hospital deaths within 30 days of emergency admission or of elective surgery.

Results We examined 2982570 hospital records; adjusted odds of 30-day death were higher for weekend emergency admissions to 11 hospitals in England (OR 1.08, 95\% Cl 1.04 to 1.13 on Sunday), 5 hospitals in USA (OR 1.13, $95 \% \mathrm{Cl} 1.04$ to 1.24 on Sunday) and 6 hospitals in the Netherlands (OR 1.20,95\% Cl 1.09 to 1.33 on Saturday). Emergency admissions to the six Australian hospitals showed no daily variation in adjusted 30-day mortality, but showed a weekend effect at 7 days post emergency admission (OR 1.12, 95\% Cl 1.04 to 1.22 on Saturday). All weekend elective patients showed higher adjusted odds of 30-day postoperative death; we observed a 'Friday effect' for elective patients in the six Dutch hospitals.

Conclusions We show that mortality outcomes for our sample vary within each country and per day of the week in agreement with previous studies of the 'weekend effect'. Due to limitations of administrative datasets, we cannot determine the reasons for these findings: however, the international nature of our database suggests that this is a systematic phenomenon affecting healthcare providers across borders. Further investigation is needed to understand the factors that give rise to the weekend effect. The participating hospitals represent varied models of service delivery, and there is a potential to learn from best practice in different healthcare systems.

\section{INTRODUCTION}

Over the last few years, an increasing number of studies have documented an association between weekend hospital admissions and higher rate of mortality, the so-called 'weekend effect'. Research from English and Scottish hospitals has shown a significant increase in the risk of death for emergency patients admitted on a weekend, even after adjusting for possible confounders. ${ }^{1-3}$ Similar trends have been observed for elective admissions; a recent study showed that patients undergoing elective surgery later in the week presented higher risk of death compared with patients having surgery on a Monday, ${ }^{4}$ although some high-risk procedures did not show significant higher mortality on weekends compared with a weekday. ${ }^{4}$ A large study of emergency admissions to New South Wales hospitals ${ }^{5}$ suggests that the weekend effect might be specific to some diagnoses and procedure groups only, and many studies report higher mortality for emergency patients admitted with some specific diagnoses on a weekend. ${ }^{6-15}$ In spite of this mounting evidence, controversy still exists as to the causes of the end-of-the-week effect. Unconfirmed factors include understaffing in hospital wards (at night and at the weekend), inadequate numbers of experienced doctors on Fridays/weekends, different patient case-mix over weekends compared with weekdays and reduced availability of testing facilities. ${ }^{16}$ 
The Global Comparators (GC) project (http:// drfosterintelligence.co.uk/global-comparators/) is an international collaboration of hospitals for mutual learning and improvement. Administrative data submitted by participant hospitals are combined into a project database, facilitating outcome comparison for in-hospital mortality, readmissions and lengths of stay across many clinical diagnoses and procedure groups. At present, 10 countries (50 hospitals) have joined the project (England, USA, Australia, the Netherlands, Italy, Belgium, Denmark, Norway, Spain and Finland).

In this paper, we take advantage of this unique international dataset to investigate whether the weekend effect is a common phenomenon occurring in other international healthcare systems. For this purpose, we calculate 30-day in-hospital mortality rates by day of the week following an emergency admission or non-emergency surgery for a sample of hospitals within four countries contributing the most records in the project.

\section{METHODS}

The GC dataset collects electronic inpatient records from administrative discharge data provided by each of the participating hospitals, which are later integrated into a uniform dataset. This process is described elsewhere. ${ }^{17}$ On average, the dataset gets updated every 6 months. We used data from the four most recent and complete calendar years, 2009-2012.

Only some countries distinguish between an urgent admission (ie, patient is not clinically compromised/ disadvantaged by a short delay) and an emergency admission (ie, patient requires admission within $24 \mathrm{~h}$ ). The GC dataset, therefore, had to group together emergency and urgent admissions under a single emergency flag. ${ }^{17}$ Each emergency admission was assigned 1 of 259 diagnostic groups based on its primary diagnosis field (Clinical Classification Software (CCS), Agency for Healthcare Research \& Quality (AHRQ)). Each elective surgical admission was assigned a principal procedure group following a literature review and consultation with surgeons and coders in each country. ${ }^{17}$

We selected records containing information on age, gender, type of admission (either elective or emergency), type of transfer if any (in or out of hospital), principal diagnosis code (International Classification of Diseases, ICD-9 or ICD-10), CCS diagnostic group, admission date, principal procedure code, date of procedure, discharge date (date of death if admission ended in death) and in-hospital death. Each record was assigned a comorbidity score based on the Elixhauser index ${ }^{18}$ plus dementia, derived from secondary diagnoses and given weights tailored to the diagnosis or procedure group. ${ }^{17}$

We excluded records corresponding to day-surgery/ day-cases, non-acute care and all records with missing or invalid entries for pseudonymised patient identifier or other key fields. Due to the difficulty in some countries in distinguishing patients admitted for observation only from those admitted as inpatients, we also excluded short-term emergency admissions not ending in death or transfer within $24 \mathrm{~h}$ and with no recorded major procedure. ${ }^{17}$

The mortality outcome was defined as an in-hospital death occurring within 30 days of an emergency admission or within 30 days of the surgical procedure taking place.

Our analysis accommodates the clustered nature of our database by using a three-level mixed model (patient, hospital, country). As we were not interested in identifying mortality variation due to specific hospitals, hospitals were considered as random-effects variables while the country to which hospitals belonged was a fixed-effects variable. We used a multilevel mixed-effects logistic regression model to calculate the adjusted odds of 30-day death per day of the week after an emergency admission/elective procedure compared with a Monday admission/procedure. We examined the effect of country on day-of-the-week mortality by testing for an interaction between country and day of the week. ${ }^{19}$ At patient level, the model adjusted for age, gender, transfers in from another hospital, year of admission, comorbidity score, day of the week and diagnosis/procedure risk category. Due to lack of information on illness severity, we used a diagnosis/procedure risk factor to partially account for patient's clinical profile. The risk categories were derived by ranking diagnoses or procedures into equally sized groups (five groups for diagnoses and four groups for procedures) based on the crude 30-day mortality rate for each of the principal recorded diagnoses and surgical procedures, respectively. At hospital level, we adjusted for bed numbers, as a proxy for hospital size, and for the rate of transfers out to other hospitals; all hospitals were known to be metropolitan teaching hospitals.

To examine the possibility that elective admissions for surgical procedures carried out on weekends correspond to riskier procedures than those performed on weekdays, we examined the proportion of admissions in each procedure-specific risk quartile throughout the week, and similarly for emergency admissions.

All data manipulation and analysis were carried out using SAS V.9.2 (SAS Institute, Cary, North Carolina, USA). To carry out the multilevel mixed-effects logistic regression modelling, we used PROC GLIMMIX. The overall model performance was assessed by a measure of discrimination (c statistic). Statistical tests were considered significant when $\mathrm{p}<0.05$.

\section{RESULTS}

We extracted a total of 2982570 admissions between 2009 and 2012 corresponding to 28 metropolitan teaching hospitals in four countries: England, Australia, USA and the Netherlands. Table 1 summarises sample 
Table 1 Countries, hospitals, hospital characteristics and number of records from GC dataset (2009-2012) used in our analysis, after exclusions

\begin{tabular}{|c|c|c|c|c|c|c|c|}
\hline \multirow[b]{2}{*}{ Country } & \multirow[b]{2}{*}{ Hospitals* } & \multirow{2}{*}{$\begin{array}{l}\text { Hospital } \\
\text { bedst (N) }\end{array}$} & \multicolumn{2}{|c|}{ Transfers out (\%) } & \multirow{2}{*}{$\begin{array}{l}\text { Emergency } \\
\text { ( } \% \text { of country) }\end{array}$} & \multirow{2}{*}{$\begin{array}{l}\text { Elective } \\
\text { (\% of country) }\end{array}$} & \multirow{2}{*}{$\begin{array}{l}\text { Total records } \\
\text { (\% of sample) }\end{array}$} \\
\hline & & & Elective & Emergency & & & \\
\hline England (11) & $\begin{array}{r}1 \\
2 \\
3 \\
4 \\
5 \\
6 \\
7 \\
8 \\
9 \\
10 \\
11\end{array}$ & $\begin{array}{r}608 \\
933 \\
2066 \\
658 \\
1134 \\
860 \\
438 \\
1376 \\
963 \\
1662 \\
1036\end{array}$ & $\begin{array}{l}1.6 \\
0.9 \\
0.6 \\
1.4 \\
0.5 \\
0.7 \\
0.5 \\
0.4 \\
1.8 \\
1.3 \\
0.6\end{array}$ & $\begin{array}{r}11.7 \\
5.3 \\
2.5 \\
6.8 \\
1.8 \\
2.7 \\
5.0 \\
3.6 \\
7.3 \\
4.9 \\
3.6\end{array}$ & $885864(66.4)$ & $448225(33.6)$ & $1334089(44.7)$ \\
\hline Australia (6) & $\begin{array}{l}12 \\
13 \\
14 \\
15 \\
16 \\
17\end{array}$ & $\begin{array}{r}390 \\
980 \\
1400 \\
2170 \\
740 \\
547\end{array}$ & $\begin{array}{l}4.2 \\
3.4 \\
5.3 \\
2.0 \\
5.0 \\
2.0\end{array}$ & $\begin{array}{l}21.2 \\
14.4 \\
15.8 \\
13.3 \\
15.3 \\
15.4\end{array}$ & 407807 (70.9) & $167329(29.1)$ & $575136(19.3)$ \\
\hline USA (5) & $\begin{array}{l}18 \\
19 \\
20 \\
21 \\
22\end{array}$ & $\begin{array}{r}631 \\
793 \\
1057 \\
781 \\
2294\end{array}$ & $\begin{array}{r}12.7 \\
12.5 \\
12.9 \\
18.7 \\
6.7\end{array}$ & $\begin{array}{l}20.2 \\
16.7 \\
19.2 \\
23.1 \\
15.6\end{array}$ & $431698(56.9)$ & $326482(43.1)$ & $758180(25.4)$ \\
\hline The Netherlands (6) & $\begin{array}{l}23 \\
24 \\
25 \\
26 \\
27 \\
28\end{array}$ & $\begin{array}{r}715 \\
1066 \\
963 \\
1042 \\
733 \\
882\end{array}$ & $\begin{array}{r}4.5 \\
5.9 \\
9.7 \\
7.8 \\
11.7 \\
8.6\end{array}$ & $\begin{array}{l}10.3 \\
12.1 \\
13.6 \\
10.1 \\
19.4 \\
19.2\end{array}$ & $160086(50.8)$ & $155079(49.2)$ & 315165 (10.6) \\
\hline
\end{tabular}

${ }^{*}$ All hospitals are metropolitan teaching centres.

tNumber of beds as published on hospitals own websites.

GC, Global Comparators.

contributions per country. Figure 1 shows all exclusions considered in our analysis.

England contributed the most to our sample, with $44.7 \%$ of the total records belonging to English hospitals. The smallest contribution is from the Netherlands, corresponding to $10.6 \%$ of the total sample. Descriptive statistics for emergency and elective admissions are presented in table 2. There were significant differences in age, gender and comorbidity score, per country $(\mathrm{p}<0.0001)$, with the patients in the six Dutch hospitals notably younger than the rest.

\section{Elective admissions}

We analysed a total of 1097115 records for patients admitted to hospitals for elective procedures between 2009 and 2012, approximately one-third of our sample $(36.8 \%)$. The proportion of elective procedures within each country was varied; the six hospitals in Australia showed the lowest proportion of elective surgical admissions at 29.1\%, while the six hospitals in the Netherlands showed the highest at 49.2\% (table 1).

Deaths

Following elective surgical procedures, there were a total of 4468 deaths within 30 days of the elective procedure taking place, giving an overall 30-day crude mortality rate of $0.41 \%$ for this sample of hospitals. There was a significant twofold difference in crude mortality $(p<0.0001)$ : The 11 hospitals in England showed the lowest rate at $0.33 \%$, followed by the 6 Australian hospitals at $0.36 \%$, the 5 US hospitals at $0.42 \%$, while the 6 Dutch hospitals showed the highest 30-day mortality rate for elective procedures at $0.64 \%$.

Crude mortality by day of the week

The number of elective procedures was considerably smaller on weekends; on average, weekend elective surgical procedures were a fraction $(3.2 \%)$ of the total number of elective procedures on weekdays (table 3 ), with country-level variation between $1.7 \%$ (for the five hospitals in USA) and 4.3\% (for the six Dutch hospitals).

Crude mortality rates and unadjusted odds of death following elective procedures varied per day of the week as shown in table 3 .

Adjusted mortality by day of the week: multilevel analysis

Results of multilevel analysis are shown in table 4 . The estimated variance for hospital effect was 0.039 with an SE of 0.015 , indicating significant outcome 


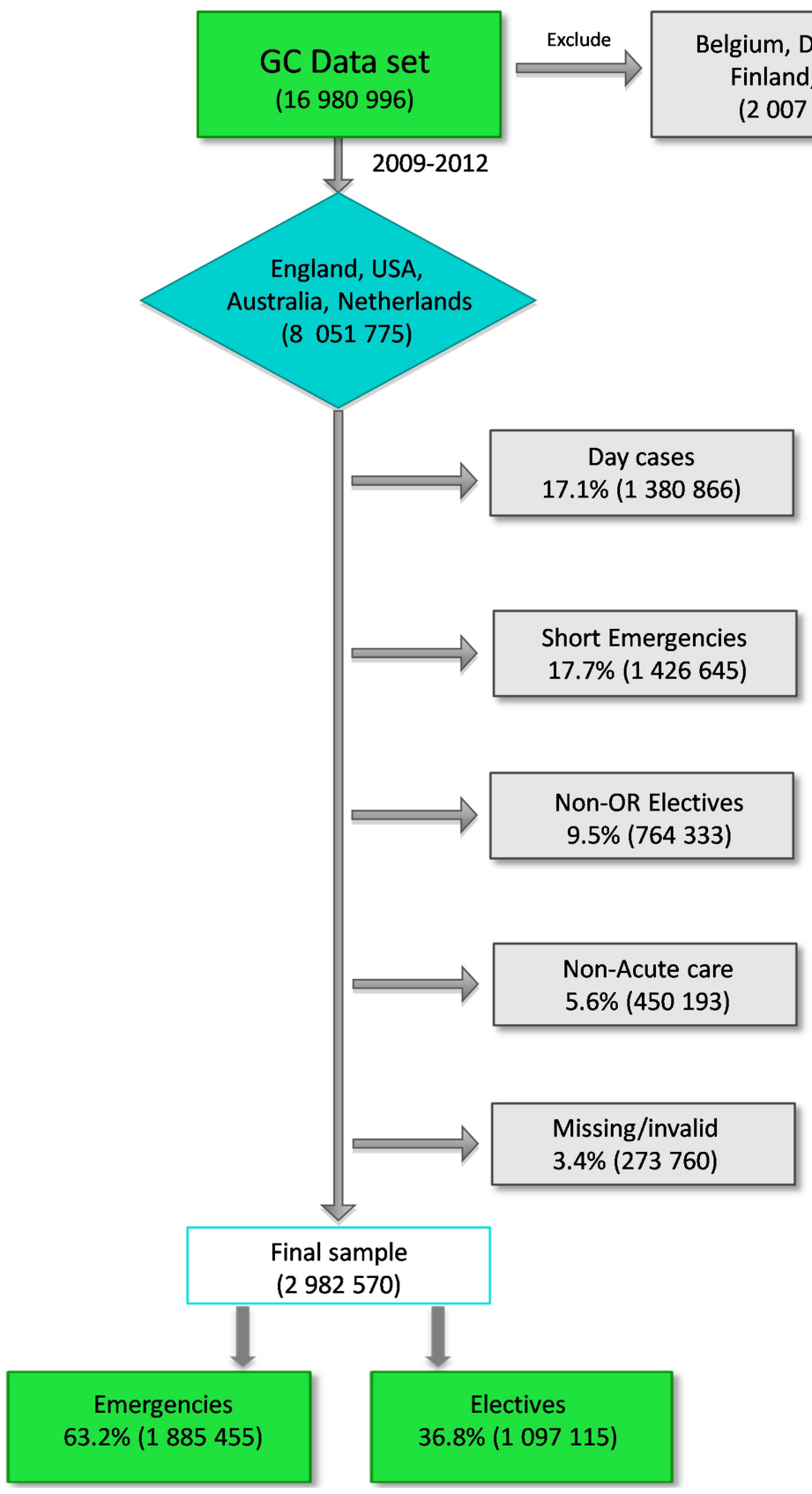

Figure 1 Flowchart of exclusions applied to the unprocessed Global Comparators (GC) dataset.

variation between hospitals that carried out elective procedures $(\mathrm{p}<0.0001)$.

Figure 2A shows the adjusted odds of death per day in which procedure took place. Aggregated hospital data in each country showed significant higher odds of 30-day death on Saturday, Sunday or both, compared with procedures performed on a Monday. A Friday effect is also observed in the six Dutch

Table 2 Patient characteristics for our sample*

\begin{tabular}{|c|c|c|c|c|c|c|c|c|}
\hline & \multicolumn{2}{|c|}{11 English hospitals } & \multicolumn{2}{|c|}{6 Australian hospitals } & \multicolumn{2}{|l|}{5 US hospitals } & \multicolumn{2}{|c|}{6 Dutch hospitals } \\
\hline & Emergency & Elective & Emergency & Elective & Emergency & Elective & Emergency & Elective \\
\hline $\begin{array}{l}\text { Mean age, } \\
\text { years (SD) }\end{array}$ & $58.3(25.8)$ & $55.3(20.0)$ & $58.1(25.3)$ & $54.8(20.2)$ & $53.9(21.9)$ & $54.9(17.5)$ & $48.7(26.9)$ & $49.1(22.8)$ \\
\hline $\begin{array}{l}\text { Male } \\
\text { admissions (\%) }\end{array}$ & $429628(48.5)$ & $211384(47.2)$ & $211409(51.8)$ & $87835(52.5)$ & $181122(42.0)$ & $144749(44.3)$ & $82162(51.3)$ & $76468(49.3)$ \\
\hline $\begin{array}{l}\text { Comorbidity } \\
\text { score (SD) }\end{array}$ & $6.6(11.1)$ & $2.4(6.8)$ & $7.3(12.5)$ & $3.9(8.9)$ & $8.6(14.9)$ & $4.2(11.8)$ & $4.4(8.7)$ & $2.2(5.9)$ \\
\hline
\end{tabular}


Table 3 Crude mortality rate* and adjusted ORs for deatht for elective surgery per day of the week, by country (2009-2012): all procedures

\begin{tabular}{|c|c|c|c|c|c|c|c|}
\hline Country & Monday & Tuesday & Wednesday & Thursday & Friday & Saturday & Sunday \\
\hline \multicolumn{8}{|l|}{ England-11 hospitals } \\
\hline Elective admissions & 83074 & 94171 & 92401 & 91239 & 71584 & 11566 & 4190 \\
\hline Deaths (1479) & 269 & 236 & 340 & 303 & 251 & 37 & 43 \\
\hline Crude rate (\%) & 0.32 & 0.25 & 0.37 & 0.33 & 0.35 & 0.32 & 1.03 \\
\hline Unadjusted OR (95\% Cl) & 1 & $0.77(0.65$ to 0.92$)$ & 1.14 (0.97 to 1.33$)$ & $1.03(0.87$ to 1.21$)$ & $1.08(0.91$ to 1.29$)$ & 0.99 (0.70 to 1.39$)$ & 3.17 (2.29 to 4.38$)$ \\
\hline Adjusted OR (95\% Cl) & 1 & 0.81 (0.67 to 0.97$)$ & 1.11 (0.93 to 1.32$)$ & $0.98(0.82$ to 1.18$)$ & 1.10 (0.91 to 1.33$)$ & 1.31 (0.90 to 1.91$)$ & 2.78 (1.93 to 4.03$)$ \\
\hline \multicolumn{8}{|l|}{ Australia-6 hospitals } \\
\hline Elective admissions & 30650 & 35167 & 35023 & 33497 & 26987 & 2222 & 3783 \\
\hline Deaths (608) & 99 & 110 & 114 & 115 & 91 & 29 & 50 \\
\hline Crude rate (\%) & 0.32 & 0.31 & 0.33 & 0.34 & 0.34 & 1.31 & 1.32 \\
\hline Unadjusted OR (95\% Cl) & 1 & $0.97(0.74$ to 1.27$)$ & 1.01 (0.77 to 1.32$)$ & 1.06 (0.81 to 1.39$)$ & 1.04 (0.78 to 1.39$)$ & 4.04 (2.67 to 6.13$)$ & 4.09 (2.91 to 5.76$)$ \\
\hline Adjusted OR $(95 \% \mathrm{Cl})$ & 1 & $0.85(0.60$ to 1.21$)$ & 0.93 (0.66 to 1.30$)$ & 0.89 (0.62 to 1.26$)$ & 1.07 (0.74 to 1.54$)$ & 1.20 (0.57 to 2.55$)$ & 2.07 (1.16 to 3.70$)$ \\
\hline \multicolumn{8}{|l|}{ USA-5 hospitals } \\
\hline Elective admissions & 68182 & 74723 & 63586 & 62689 & 51959 & 3350 & 1993 \\
\hline Deaths (1381) & 225 & 285 & 275 & 284 & 235 & 44 & 33 \\
\hline Crude rate (\%) & 0.33 & 0.38 & 0.43 & 0.45 & 0.45 & 1.31 & 1.66 \\
\hline Unadjusted OR (95\% Cl) & 1 & 1.16 (0.97 to 1.38$)$ & 1.31 (1.10 to 1.56$)$ & $1.37(1.15$ to 1.64$)$ & 1.37 (1.14 to 1.65$)$ & 3.98 (2.88 to 5.51$)$ & 5.02 (3.47 to 7.25$)$ \\
\hline Adjusted OR $(95 \% \mathrm{Cl})$ & 1 & $1.37(1.00$ to 1.87$)$ & 1.38 (1.00 to 1.90$)$ & 1.27 (0.91 to 1.76$)$ & 1.18 (0.84 to 1.66$)$ & 2.48 (1.17 to 5.23$)$ & 2.35 (0.61 to 9.04$)$ \\
\hline \multicolumn{8}{|l|}{ The Netherlands— 6 hospitals } \\
\hline Elective admissions & 30683 & 33662 & 30683 & 30243 & 23353 & 2229 & 4226 \\
\hline Deaths (1000) & 174 & 166 & 198 & 193 & 170 & 42 & 57 \\
\hline Crude rate (\%) & 0.57 & 0.49 & 0.65 & 0.64 & 0.73 & 1.88 & 1.35 \\
\hline Unadjusted OR (95\% Cl) & 1 & 0.87 (0.70 to 1.08$)$ & $1.14(0.93$ to 1.40$)$ & 1.13 (0.92 to 1.38$)$ & 1.28 (1.04 to 1.59$)$ & 3.32 (2.37 to 4.67$)$ & 2.38 (1.76 to 3.21$)$ \\
\hline Adjusted OR $(95 \% \mathrm{Cl})$ & 1 & 0.88 (0.71 to 1.10$)$ & $1.14(0.92$ to 1.40$)$ & 1.19 (0.99 to 1.48$)$ & 1.33 (1.07 to 1.66$)$ & 4.74 (3.29 to 6.82$)$ & 2.61 (1.86 to 3.66$)$ \\
\hline
\end{tabular}

*30-day in-hospital after procedure.

tORs adjusted for age, gender, year of admission, transfer in, procedure risk, comorbidity score, hospital beds, transfer-out rate and day of procedure. Odds are relative to a procedure taking place on a Monday. 
Table 4 Adjusted odds of 30-day death for elective and emergency admissions

\begin{tabular}{|c|c|c|}
\hline & $\begin{array}{l}\text { Elective } \\
\text { OR }(95 \% \mathrm{Cl})\end{array}$ & $\begin{array}{l}\text { Emergency } \\
\text { OR }(95 \% \mathrm{Cl})\end{array}$ \\
\hline \multicolumn{3}{|l|}{ Patient fixed effects } \\
\hline Gender, male vs female & $1.033(0.956$ to 1.116$)$ & $1.062(1.045$ to 1.080$)$ \\
\hline Aget & 1.026 (1.023 to 1.028$)$ & $1.026(1.025$ to 1.026$)$ \\
\hline Comorbidity score $†$ & $1.092(1.089$ to 1.095$)$ & $1.044(1.043$ to 1.044$)$ \\
\hline Transfers in vs not & 3.413 (3.003 to 3.891$)$ & $1.513(1.468$ to 1.560$)$ \\
\hline \multicolumn{3}{|l|}{ Year of admission } \\
\hline 2009 vs 2012 & $1.301(1.152$ to 1.469$)$ & 1.209 (1.179 to 1.241$)$ \\
\hline 2010 vs 2012 & 1.217 (1.077 to 1.374$)$ & 1.099 (1.071 to 1.128$)$ \\
\hline 2011 vs 2012 & $1.192(1.057$ to 1.343$)$ & $1.043(1.017$ to 1.070$)$ \\
\hline \multicolumn{3}{|l|}{ Ranking (lowest risk=0) } \\
\hline 0 vs 3 & $0.102(0.080$ to 0.131$)$ & $0.044(0.040$ to 0.048$)$ \\
\hline 1 vs 3 & 0.335 (0.298 to 0.375$)$ & $0.149(0.145$ to 0.154$)$ \\
\hline 2 vs 3 & 0.684 (0.596 to 0.785$)$ & 0.291 (0.285 to 0.296$)$ \\
\hline \multicolumn{3}{|l|}{ Country } \\
\hline England vs USA & 0.996 (0.571 to 1.737$)$ & 2.109 (1.307 to 3.402$)$ \\
\hline Australia vs USA & 0.596 (0.367 to 0.966$)$ & 1.454 (0.947 to 2.232$)$ \\
\hline The Netherlands vs USA & 3.310 (2.179 to 5.027$)$ & 2.708 (1.743 to 4.207$)$ \\
\hline \multicolumn{3}{|l|}{ Country $x$ day of the week } \\
\hline \multicolumn{3}{|l|}{ England } \\
\hline Tuesday vs Monday & 0.81 (0.67 to 0.97$)$ & 0.97 (0.94 to 1.01$)$ \\
\hline Wednesday vs Monday & 1.11 (0.93 to 1.32$)$ & $0.96(0.93$ to 1.00$)$ \\
\hline Thursday vs Monday & $0.98(0.82$ to 1.18$)$ & $0.96(0.92$ to 0.99$)$ \\
\hline Friday vs Monday & $1.10(0.91$ to 1.33$)$ & 0.98 (0.94 to 1.01$)$ \\
\hline Saturday vs Monday & $1.31(0.90$ to 1.91$)$ & 1.07 (1.03 to 1.12$)$ \\
\hline Sunday vs Monday & 2.78 (1.93 to 4.03$)$ & $1.08(1.04$ to 1.13$)$ \\
\hline \multicolumn{3}{|l|}{ Australia } \\
\hline Tuesday vs Monday & 0.85 (0.60 to 1.21$)$ & 0.95 (0.90 to 1.02$)$ \\
\hline Wednesday vs Monday & $0.93(0.66$ to 1.30$)$ & 0.94 (0.89 to 1.01$)$ \\
\hline Thursday vs Monday & 0.89 (0.62 to 1.26$)$ & 0.98 (0.92 to 1.06$)$ \\
\hline Friday vs Monday & $1.07(0.74$ to 1.54$)$ & 0.97 (0.91 to 1.04$)$ \\
\hline Saturday vs Monday & $1.20(0.57$ to 2.55$)$ & $1.03(0.97$ to 1.10$)$ \\
\hline Sunday vs Monday & 2.07 (1.16 to 3.70$)$ & 1.02 (0.95 to 1.09$)$ \\
\hline \multicolumn{3}{|l|}{ USA } \\
\hline Tuesday vs Monday & $1.37(1.00$ to 1.87$)$ & 0.98 (0.92 to 1.05$)$ \\
\hline Wednesday vs Monday & $1.38(1.00$ to 1.90$)$ & 1.00 (0.93 to 1.07$)$ \\
\hline Thursday vs Monday & $1.27(0.91$ to 1.76$)$ & 1.07 (1.00 to 1.15$)$ \\
\hline Friday vs Monday & $1.18(0.84$ to 1.66$)$ & 1.05 (0.98 to 1.12$)$ \\
\hline Saturday vs Monday & $2.48(1.17$ to 5.23$)$ & $1.11(1.02$ to 1.20$)$ \\
\hline Sunday vs Monday & 2.35 (0.61 to 9.04$)$ & $1.13(1.04$ to 1.24$)$ \\
\hline \multicolumn{3}{|l|}{ The Netherlands } \\
\hline Tuesday vs Monday & $0.88(0.71$ to 1.10$)$ & $1.06(0.96$ to 1.16$)$ \\
\hline Wednesday vs Monday & $1.14(0.92$ to 1.40$)$ & $1.06(0.97$ to 1.17$)$ \\
\hline Thursday vs Monday & $1.19(0.99$ to 1.48$)$ & $1.03(0.94$ to 1.13$)$ \\
\hline Friday vs Monday & $1.33(1.07$ to 1.66$)$ & $0.98(0.90$ to 1.08$)$ \\
\hline Saturday vs Monday & 4.74 (3.29 to 6.82$)$ & $1.20(1.09$ to 1.33$)$ \\
\hline Sunday vs Monday & 2.61 (1.86 to 3.66$)$ & $1.17(1.06$ to 1.29$)$ \\
\hline \multicolumn{3}{|l|}{ Hospital fixed effects } \\
\hline Bedst & $1.000(1.000 \text { to } 1.000)^{*}$ & $1.000(1.000 \text { to } 1.000)^{*}$ \\
\hline Transfers out $\dagger$ & $0.948(0.918 \text { to } 0.979)^{* *}$ & $0.997(0.977 \text { to } 1.016)^{*}$ \\
\hline \multicolumn{3}{|l|}{ Random effects (hospitals) } \\
\hline Covariance parameter estimates (SD) & $0.0395(0.0150)^{* * *}$ & $0.1129(0.0218)^{* * *}$ \\
\hline c Statistic & 0.878 & 0.856 \\
\hline
\end{tabular}




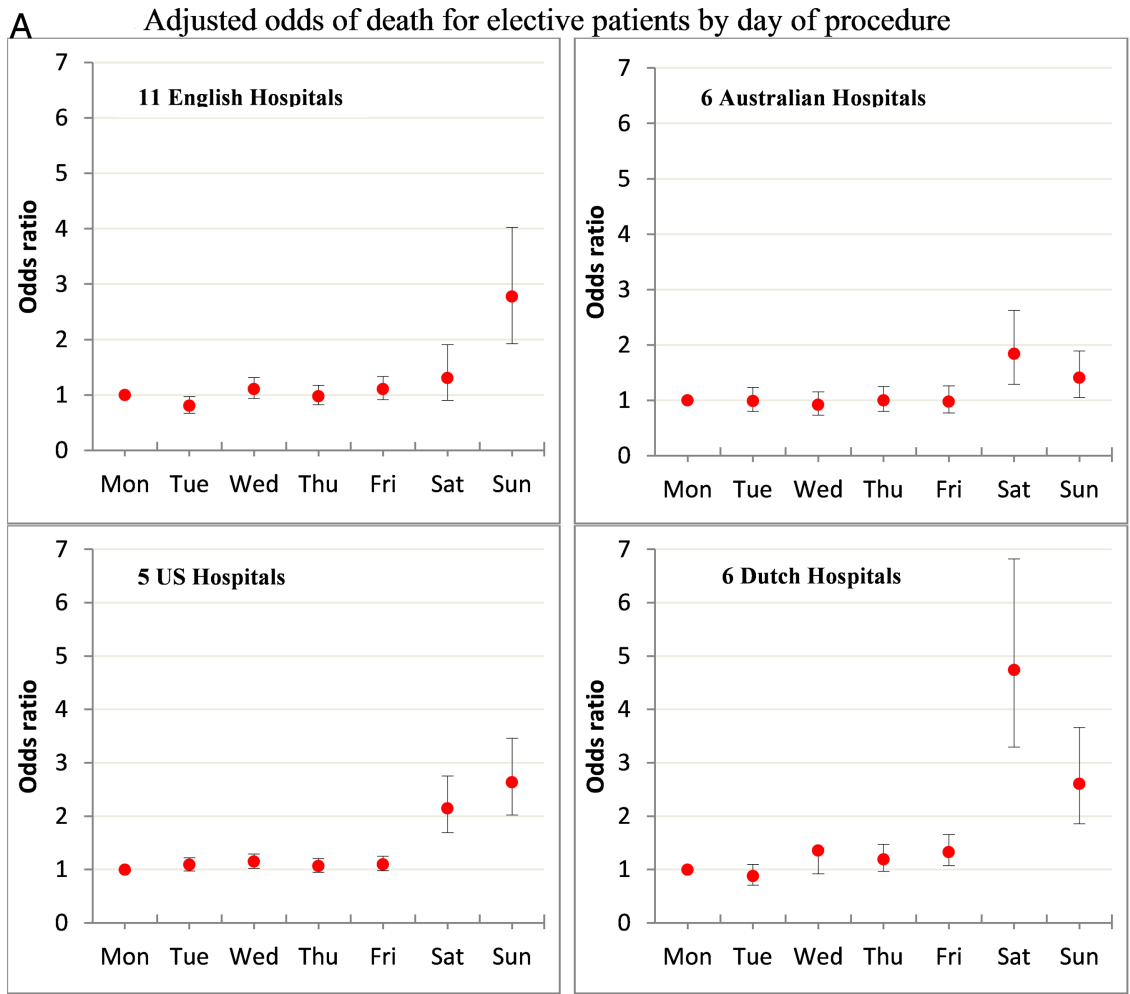

B Adjusted odds of death for emergency patients by day of admission

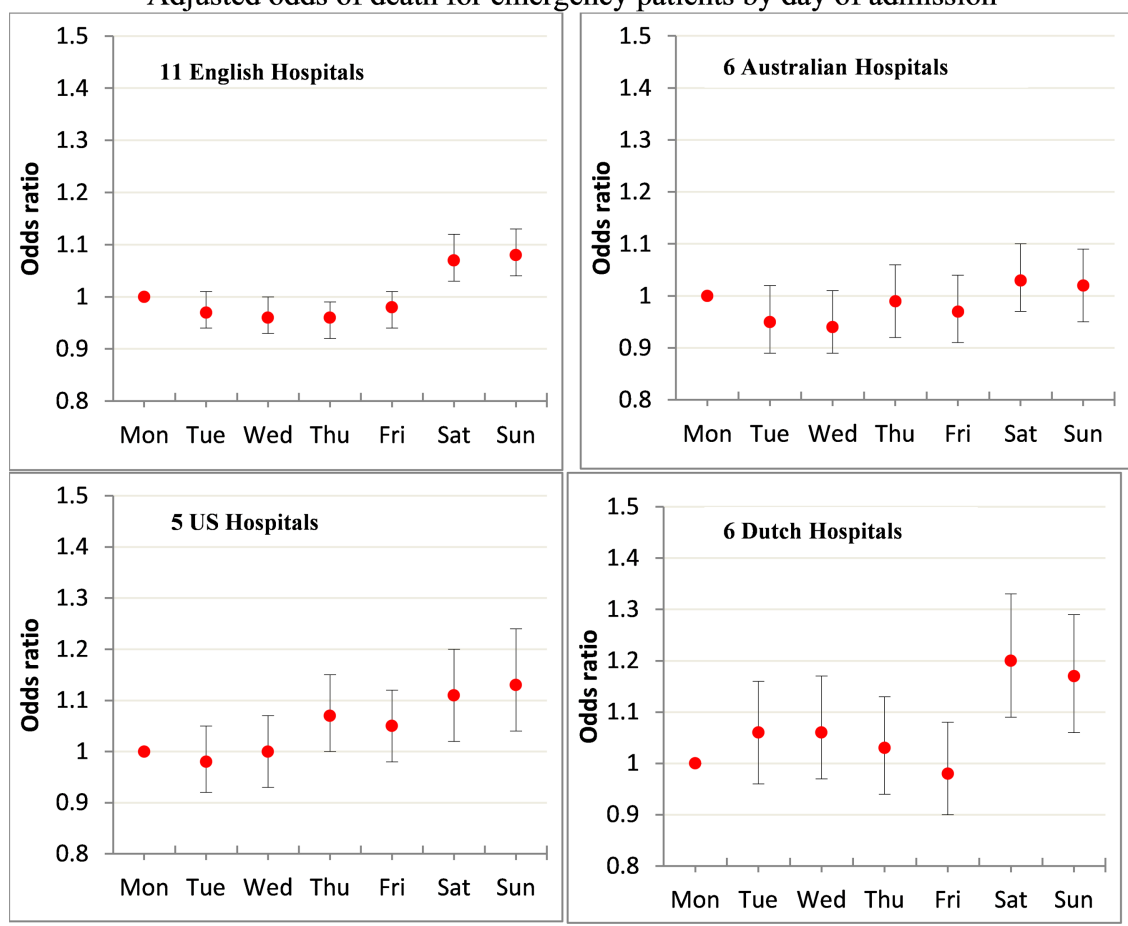

Figure 2 (A) Adjusted odds of death for elective admissions by day of procedure. (B) Adjusted odds of death for emergency admissions by day of admission

hospitals for elective patients. Table 5 shows the ratio of ORs comparing odds of 30-day deaths with those for a Monday procedure in the five US hospitals. We observe a steady increase in the odds of 30-day death per day of the week as we approach the weekend for elective patients in the 11 English and 5 US hospitals. This trend supports the hypothesised idea that the first $48 \mathrm{~h}$ of postoperative care is critical for the hospitalised patient. ${ }^{4}$

The distribution of procedure-specific risk throughout the week varies for the sampled hospitals within each country; notably, the six Australian hospitals seem to perform a larger proportion of riskier procedures on weekends $33 \%$ of total procedures on 


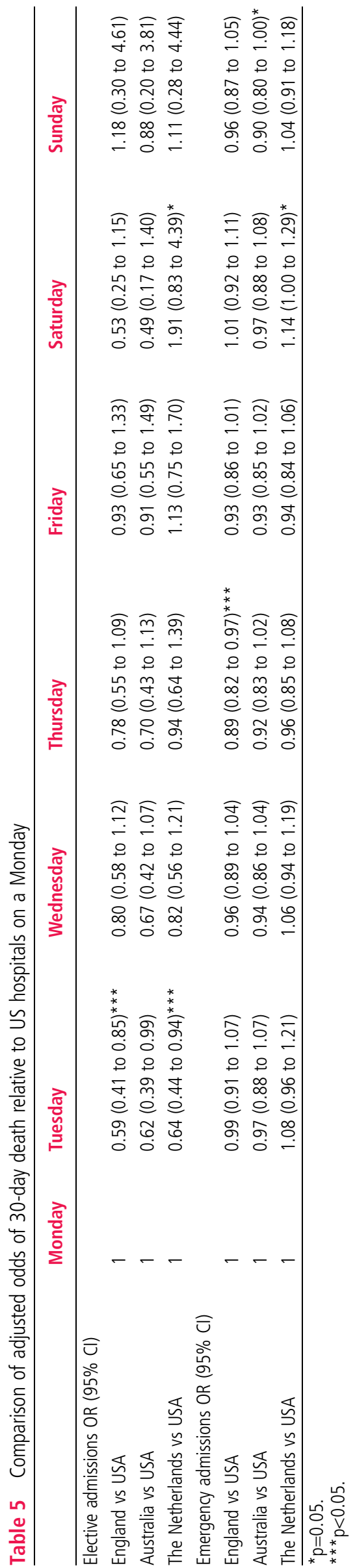

weekends) compared with the rest of the week $(22 \%$ of total procedures on weekdays). The five US hospitals perform a lower proportion of high-risk procedures on the weekends at 30\% compared with 35\% during weekdays. The 11 hospitals in England and the 6 Dutch hospitals present a balanced distribution of procedure risk between weekdays and weekends: for the 11 hospitals in England, 39\% of weekend procedures are high risk compared with $38 \%$ on weekdays; for the six Dutch hospitals, these figures are 33\% and $34 \%$, respectively (see online supplementary figure A1 in appendix).

\section{Emergency admissions}

We analysed a total of 1885455 emergency admissions between 2009 and $2012 \quad(63.2 \%$ of total sample). There was large variation in the proportion of emergency admissions between countries; the six Australian hospitals had the largest proportion at $70.9 \%$, while the six Dutch hospitals had the lowest at $50.8 \%$ (table 1 ).

Deaths

A total of 73636 in-hospital deaths were recorded following an emergency admission and within 30 days of the admission date, giving an overall crude 30-day mortality rate of $3.9 \%$. The overall crude mortality rate per country showed significant differences $(p<0.05)$. The 11 English hospitals showed the highest crude mortality at $4.6 \%$ followed by the 6 Dutch hospitals at $4.2 \%$, while the 5 US hospitals showed the lowest mortality at $2.7 \%$ followed by the 6 Australian hospitals at 3.5\%.

Crude mortality by day of the week

There were on average $31.8 \%$ fewer emergency admissions at weekends compared with weekdays (table 6). The 30 day crude mortality rates following emergency admissions varied per day of the week. Moreover, aggregated hospital data in each country showed higher 30-day crude mortality rates at weekends compared with weekdays, with the exception of the six Australian hospitals, which showed a consistent rate $(3.6 \%)$ across the whole week.

Adjusted mortality by day of the week: multilevel analysis

Results of multilevel analysis for emergency admissions are shown in table 4 . The estimated variance for hospital effect was 0.1129 with an SE of 0.0218 , indicating significant outcome variation between hospitals that admitted emergency patients $(p<0.0001)$.

Figure $2 \mathrm{~B}$ shows the adjusted odds of death per day of admission. Emergency patients in the English, US and Dutch hospitals showed significant higher adjusted odds of deaths $(p<0.0001)$ on Saturdays and Sundays compared with a Monday admission. Emergency patients admitted to the six Dutch hospitals had the highest adjusted OR of 30-day death at 1.20 and $1.17(\mathrm{p}<0.05)$ for Saturday and Sunday, 
Table 6 Crude mortality rate* and ORs for deatht after emergency admissions per day of the week, by country (2009-2012): all diagnoses

\begin{tabular}{|c|c|c|c|c|c|c|c|}
\hline Country & Monday & Tuesday & Wednesday & Thursday & Friday & Saturday & Sunday \\
\hline \multicolumn{8}{|l|}{ England-11 hospitals } \\
\hline Emergency admissions & 139555 & 135661 & 132064 & 127854 & 135403 & 109656 & 105671 \\
\hline Deaths (40 749) & 6344 & 6084 & 5890 & 5789 & 6136 & 5346 & 5160 \\
\hline Crude rate (\%) & 4.5 & 4.5 & 4.5 & 4.5 & 4.5 & 4.9 & 4.9 \\
\hline Unadjusted OR (95\% CI) & 1 & 0.99 (0.95 to 1.02$)$ & 0.98 (0.95 to 1.02$)$ & $1.00(0.96$ to 1.03$)$ & $1.00(0.96$ to 1.03$)$ & 1.07 (1.03 to 1.11$)$ & 1.07 (1.03 to 1.12$)$ \\
\hline Adjusted OR (95\% Cl) & 1 & $0.97(0.94$ to 1.01$)$ & $0.96(0.93$ to 1.00$)$ & 0.96 (0.92 to 0.99$)$ & $0.98(0.94$ to 1.01$)$ & 1.07 (1.03 to 1.12$)$ & 1.08 (1.04 to 1.13$)$ \\
\hline \multicolumn{8}{|l|}{ Australia-6 hospitals } \\
\hline Emergency admissions & 63719 & 60909 & 60200 & 58724 & 60236 & 52574 & 51445 \\
\hline Deaths (14 450) & 2280 & 2111 & 2078 & 2118 & 2156 & 1883 & 1824 \\
\hline Crude rate (\%) & 3.6 & 3.5 & 3.5 & 3.6 & 3.6 & 3.6 & 3.6 \\
\hline Unadjusted OR (95\% CI) & 1 & $0.97(0.91$ to 1.03$)$ & $0.96(0.91$ to 1.02$)$ & 1.01 (0.95 to 1.07$)$ & $1.00(0.94$ to 1.06$)$ & $1.00(0.94$ to 1.07$)$ & 0.99 (0.93 to 1.05$)$ \\
\hline Adjusted OR (95\% Cl) & 1 & 0.95 (0.90 to 1.02$)$ & 0.94 (0.89 to 1.01$)$ & $0.98(0.92$ to 1.06$)$ & $0.97(0.91$ to 1.04$)$ & $1.03(0.97$ to 1.10$)$ & 1.02 (0.95 to 1.09$)$ \\
\hline \multicolumn{8}{|l|}{ USA-5 hospitals } \\
\hline Emergency admissions & 68377 & 69293 & 66348 & 64587 & 66395 & 49658 & 47040 \\
\hline Deaths (11 645) & 1808 & 1732 & 1716 & 1768 & 1778 & 1421 & 1422 \\
\hline Crude rate (\%) & 2.6 & 2.5 & 2.6 & 2.7 & 2.7 & 2.9 & 3.0 \\
\hline Unadjusted OR (95\% CI) & 1 & 0.95 (0.88 to 1.01$)$ & $0.98(0.91$ to 1.05$)$ & $1.04(0.97$ to 1.11$)$ & 1.01 (0.95 to 1.08$)$ & $1.08(1.01$ to 1.16$)$ & 1.14 (1.07 to 1.23$)$ \\
\hline Adjusted OR (95\% CI) & 1 & $0.98(0.92$ to 1.05$)$ & $1.00(0.93$ to 1.07$)$ & 1.07 (1.00 to 1.15$)$ & 1.05 (0.98 to 1.12$)$ & $1.11(1.02$ to 1.20$)$ & $1.13(1.04$ to 1.24$)$ \\
\hline \multicolumn{8}{|l|}{ The Netherlands -6 hospitals } \\
\hline Emergency admissions & 25719 & 23988 & 23715 & 23179 & 24682 & 19259 & 19544 \\
\hline Deaths (6792) & 1046 & 1014 & 993 & 966 & 988 & 892 & 893 \\
\hline Crude rate (\%) & 4.1 & 4.2 & 4.2 & 4.2 & 4.0 & 4.6 & 4.6 \\
\hline Unadjusted OR (95\% CI) & 1 & $1.04(0.95$ to 1.14$)$ & $1.03(0.94$ to 1.12$)$ & $1.02(0.94$ to 1.12$)$ & $0.98(0.90$ to 1.08$)$ & $1.14(1.04$ to 1.25$)$ & 1.12 (1.03 to 1.23$)$ \\
\hline Adjusted OR (95\% CI) & 1 & $1.06(0.96$ to 1.16$)$ & 1.06 (0.97 to 1.17$)$ & $1.03(0.94$ to 1.13$)$ & $0.98(0.90$ to 1.08$)$ & $1.20(1.09$ to 1.33$)$ & 1.17 (1.06 to 1.29$)$ \\
\hline
\end{tabular}

\section{*30-day in-hospital.}

tAdjusted for age, gender, year of admission, transfer in, diagnosis quintile risk, comorbidity score, hospital beds, transfer-out rate and day of admission. Odds are relative to a Monday admission. 
respectively, compared with a Monday. Emergency patients to the six Australian hospitals showed no significant increase in adjusted odds of 30-day death on any day of the week compared with a Monday emergency admission. Table 5 shows the ratio of adjusted ORs comparing adjusted odds of 30-day deaths with those for a Monday emergency admission to a US hospital.

To investigate the possibility that weekend emergency admissions correspond to patients presenting with particularly life-threatening diagnoses compared with those admitted on a weekday, we examined the proportion of patients in each diagnosis risk quintile per day of the week. We observe an overall homogeneous distribution of diagnosis-specific risk among the days of the week for the sampled hospitals within each country (see online supplementary figure A2 in appendix).

\section{DISCUSSION}

Using a uniquely available international dataset, we have examined records of emergency and elective admissions from metropolitan teaching hospitals in four countries participating in the GC project (England, Australia, USA and the Netherlands) over a period of 4 years (2009-2012). Our main finding is that mortality outcomes, for the sample of hospitals considered, vary within each country and per day of the week in agreement with previous analysis showing a 'weekend effect' for emergency and elective admissions. ${ }^{1249162021}$

According to the literature, crude mortality rates vary among countries; in the Netherlands, elective surgical admissions show a mortality rate of $2.0 \%,{ }^{22}$ while mortality rate for emergency admissions is $4.9 \% .^{23}$ Due to the difficulty to differentiate electives and emergencies in US admissions, an overall mortality rate for inpatient admissions of $1.84 \%$ is reported $^{24}$; similarly, for Australian inpatients, mortality rate is $0.75 \% .{ }^{25}$ In England, a cohort of elective inpatients shows an overall mortality rate of $0.67 \%,{ }^{4}$ while emergency admissions show a crude mortality rate of $4.98 \% .^{2}$ Overall, our observations are in agreement with these crude mortality rates.

\section{Elective surgical admissions}

After adjusting for patient case-mix, hospital characteristics and country, the adjusted odds of 30-day death following elective surgery remained significantly high when surgery took place on a Friday, Saturday and/or Sunday compared with a Monday procedure. This suggests that other processes involved in the care of these patients were not accounted for in our analysis. These results confirm previous studies that showed increased mortality for end-of-the-week elective surgery. ${ }^{4}{ }^{26-28}$ The six Dutch hospitals also showed a 'Friday effect' with 33\% increased adjusted odds of 30-day death after elective procedure on a
Friday compared with a Monday. When comparing aggregated data at country level, patients having elective surgery in the 11 English and 6 Dutch hospitals on a Tuesday had significant lower adjusted odds of 30-day death compared with patients having surgery on a Monday in US hospitals.

The distribution of procedure-specific risk throughout the week was varied; notably, the six Australian hospitals seemed to perform a larger proportion of riskier procedures on weekends $(33 \%$ of total procedures on weekends) compared with the rest of the week ( $22 \%$ of total procedures on weekdays). In contrast, the five US hospitals performed a lower proportion of high-risk procedures on the weekends at 30\% compared with 35\% during weekdays. English and Dutch hospitals in the sample presented a balanced distribution of procedure risk between weekdays and weekends.

\section{Emergency admissions}

We found that the five US hospitals had the lowest crude mortality rate following an emergency admission, in agreement with a previous study. ${ }^{17}$ When examined by day of the week, crude mortality rates were higher on a weekend emergency admission compared with a weekday admission for all countries with the exception of the six Australian hospitals that showed an almost constant rate throughout the week. Interestingly, these Australian hospitals had the largest proportion of emergency admissions, while having one of the lowest 30-day crude mortality rates after an emergency admission with little or no variation throughout the week.

After adjusting for available confounders, however, weekend admissions had higher adjusted odds of 30-day death compared with a Monday admission for the English, US and Dutch hospitals $(\mathrm{p}<0.05)$ (table 6). The six hospitals in Australia did not show significant increased odds of death after 30 days of an emergency admission on any day of the week.

To check for bias due to our exclusion of short-term emergencies (the Methods section), we conducted a sensitivity test by replicating our analysis and including all emergency admissions. The results of this analysis revealed a change of $<1 \%$ in the adjusted odds of deaths per day of the week, suggesting that no bias is introduced by excluding short emergencies.

To further avoid unaccounted variations due to sicker patients being transferred out on weekends, we repeated our analysis with the exclusion of these patients. This analysis revealed an almost identical result to the original, and we can say that our results were not influenced by variation in the number of transferred-out patients per day of the week.

While measuring mortality after 30 days of admission is a common but arbitrary outcome measure, we also calculated in-hospital mortality for emergency patients after 7 days of admission; interestingly, the six Australian hospitals in our sample showed significant 
higher odds of death on a Saturday (OR 1.12, 95\% CI 1.04 to 1.22) and Sunday (OR 1.11, 95\% CI 1.03 to 1.21) compared with a Monday admission $(\mathrm{p}<0.01)$, in overall agreement with a recent study of 7-day mortality in emergency patients. ${ }^{5}$ Lack of power due to our small sample of participant hospitals from Australia could be contributing to the lack of weekend effect at 30 days post admission. This discrepancy highlights the importance of optimal timeframe choice for outcome measures, and emphasises the unresolved issue of the length of the weekend effect. Thus, overall, we confirm previous results of increased weekend mortality for emergency patients in hospitals across four countries. ${ }^{125}$

When compared with emergency admissions to US hospitals on a Monday (table 5), the sample of English, Australian and Dutch hospitals showed significant lower adjusted odds of 30-day death on a Thursday, Sunday and Saturday, respectively.

In contrast to procedure-specific risk, we observed an overall homogeneous distribution of diagnosisspecific risk among the days of the week, that is, there were no significant differences in the diagnosisspecific risk distribution between weekdays and weekends for admitted emergency patients.

As highlighted by other studies, ${ }^{17}{ }^{29}$ intercountry differences in the process of healthcare and variation in diagnostic coding systems make intercountry comparison of health outcomes challenging at best. Previous studies of mortality per day of the week have been limited to a specific patient population, either by region or by patient type (such as patients in the intensive care unit (ICU) or patients who had major trauma). Within the USA, a study in the non-elective setting ${ }^{16}$ reported a significant weekend effect $(10.5 \%$ higher mortality on weekends compared with weekdays) while a veteran affairs study for non-emergency surgical procedures revealed $17 \%$ higher adjusted odds of death for patients admitted postoperatively to regular hospital floors on Fridays compared with a Monday-to-Wednesday (inclusive) admission. ${ }^{28}$ Interestingly, ICUs have also shown a weekend effect; in Australia, a study showed that out-of-hours and weekend admissions to ICU for elective surgery were associated with higher mortality $(20 \%$ on weekends vs $14 \%$ during weekdays $)^{27}$; in the Netherlands, a study of admissions to ICU showed increased mortality during out-of-hours and at weekends. $^{30}$

A recent study of 7-day mortality in admissions via emergency departments in the Australian region of New South Wales ${ }^{5}$ showed significant weekend effect in 16 out of 430 diagnosis groups; unfortunately, this study did not provide an estimate for all emergency admissions combined. While emergency admissions at our six Australian hospitals show a flat mortality pattern throughout the week at 30 days post admission, we find that these same hospitals show significant higher weekend odds of death at 7 days post admission, consistent with their findings. Our results further confirm the association of higher mortality towards the end of the week within the elective and emergency settings with variation among countries. The reasons for this phenomenon remain unknown, but it is widely suggested that changes in human behaviour on weekends as well as restricted healthcare services on the weekends and out-of-hours are major contributors to the end-of-the-week effect. ${ }^{31}$

\section{Strengths of this study}

Our analysis is based on a unique international dataset aimed at the comparison of clinical outcomes between countries. Data collation has been homogenised, ${ }^{17}$ but limitations remain, as described in the next subsection. We have tried to account for variation in patient and hospital characteristics. Long-term time variations in hospital care were also accounted for by adjusting for year of admission. We have also eliminated daysurgery patients and short-stay emergency patients as these are possible reasons for confounding in clinical profiles. Despite this, significant differences in mortality rates for weekend versus weekday admissions were found.

\section{Limitations to our study}

The GC database has been gathered from administrative sources, which are subject to well-known criticisms, most importantly errors in clinical coding; hospitals participating in this project have performed limited validation against other databases, but no systematic chart abstraction has been carried out. However, in England, levels of reported accuracy suggest that routinely collected administrative data are sufficiently robust to support their use in research. ${ }^{17} 2932$ Another significant shortcoming in administrative datasets is the lack of information on disease severity or procedure complexity, which we have tried to overcome by adjusting for mortality risks for specific diagnosis and procedure groups.

Unfortunately, we were unable to incorporate adjustment for socioeconomic status (deprivation index), a common practice in risk models, as this information is not gathered in a comparable manner across borders.

We used records from participating hospitals, a selfselected group of acute healthcare providers striving for excellence and quality improvement. It is, therefore, possible that other hospitals in these countries could show different results from those observed in our study, such as bigger weekday differences.

While there is a desire for more detailed diagnosis or procedure-specific analysis, the number of hospitals and patients is not enough to reach sufficient statistical power, in particular when we wish to analyse by day of the week, but as the project grows, this limitation will diminish. 
Because of the difficulty of linking out-of-hospital deaths to hospital admissions, our outcomes relate to in-hospital deaths only. There is considerable variation between countries in their length of stay, and it is also possible that there might be some day-of-the-week bias in the proportion of patients remaining in hospital to die.

We are able to only identify urgent readmissions to the same hospital; unfortunately, readmissions to a hospital not participating in the GC project are lost. Thus, two consecutive emergency admissions are considered as two different admissions if they are at different participating hospitals.

Additionally, we are not able to link the death of a transferred-in patient to the original index admission, and this could bias our results by unfairly assigning deaths occurring on a weekend to a hospital where the patient ultimately dies.

\section{Other possible explanations}

The increased mortality associated with weekend emergency and elective admissions is multifactorial, and, as already pointed out, may also be specific to those diagnoses and procedures that are particularly sensitive to hospital services being reduced/absent on Saturdays and Sundays. Weekend patients may be subject to reduced and unsuitably skilled staff (less available senior staff, junior doctors in training) as well as reduced availability of diagnostics. Urgent cases needing prompt treatment on a weekend might be subject to unnecessary wait, leading to adverse outcomes. Rota changes and unfamiliar junior doctors might also count towards patient disadvantage. All of these factors are likely to negatively affect patient outcomes who are admitted on weekends reflecting the quality of care provided by hospitals.

\section{CONCLUSIONS}

Our study finds a significant 'day-of-the-week' effect for both emergency admissions and elective surgical procedures. Although these results are limited to the small number of participating hospitals, the international nature of our database suggests that this is a systematic phenomenon affecting healthcare providers across borders. The one exception is for emergency admissions at six Australian hospitals, where there is a flat mortality pattern throughout the week, at 30 days post admission, but significantly higher odds of death at 7 days post admission. Due to limitations of administrative datasets, we are not able to determine the reasons for these findings. However, these are consistent with other studies, and further investigation is needed to determine the underlying causes of the found shortcomings/patterns. There are now over 50 member institutions in 10 different countries: the UK, USA, Australia, the Netherlands, Italy, Spain, Belgium, Finland, Norway and Denmark. Adding more hospitals will further enhance the ability to tease out patterns of staffing and service delivery that affect outcomes for patients admitted on weekends. Participating hospitals represent varied models of service delivery, and there is a huge potential to learn from best practice.

Contributors All named authors meet the three criteria of (1) substantial contributions to conception and design and/or analysis and interpretation of data, (2) drafting the article or revising it critically for important intellectual content and

(3) final approval of the version to be published.

Competing interests None declared.

Provenance and peer review Not commissioned; externally peer reviewed.

Open Access This is an Open Access article distributed in accordance with the Creative Commons Attribution Non Commercial (CC BY-NC 4.0) license, which permits others to distribute, remix, adapt, build upon this work noncommercially, and license their derivative works on different terms, provided the original work is properly cited and the use is non-commercial. See: http://creativecommons.org/licenses/by$\mathrm{nc} / 4.0 /$

\section{REFERENCES}

1 Freemantle N, Richardson M, Wood J, et al. Weekend hospitalization and additional risk of death: an analysis of inpatient data. J R Soc Med 2012;105:74-84.

2 Aylin P, Yunus A, Bottle A, et al. Weekend mortality for emergency admissions. A large multicentre study. Qual Saf Health Care 2010;19:213-17.

3 Handel AE, Patel SV, Skingsley A, et al. Weekend admissions as an independent predictor of mortality: an analysis of Scottish hospital admissions. BMJ Open 2012;2:pii:e001789.

4 Aylin P, Alexandrescu R, Jen MH, et al. Day of the week procedure and 30 day mortality for elective surgery: retrospective analysis of hospital episode statistics. BMJ 2013;346:f2424.

5 Concha OP, Gallego B, Hillman K, et al. Do variations in hospital mortality patterns after weekend admission reflect reduced quality of care or different patient cohorts? A population-based study. BMJ Qual Saf 2014;23:215-22.

6 Kostis WJ, Demissie K, Marcella SW, et al. Weekend versus weekday admission and mortality from myocardial infarction. N Engl J Med 2007;356:1099-109.

7 Hong JS, Kang HC, Lee SH. Comparison of case fatality rates for acute myocardial infarction in weekday vs weekend admissions in South Korea. Circ J 2010;74:496-502.

8 Nanchal R, Kumar G, Taneja A, et al. Pulmonary embolism: the weekend effect. Chest 2012;142:690-6.

9 Bell CM, Redelmeier DA. Mortality among patients admitted to hospitals on weekends as compared with weekdays. $\mathrm{N} \mathrm{Engl} \mathrm{J}$ Med 2001;345:663-8.

10 Palmer WL, Bottle A, Davie C, et al. Dying for the weekend: a retrospective cohort study on the association between day of hospital presentation and the quality and safety of stroke care. Arch Neurol 2012;69:1296-302.

11 Niewada M, Jezierska-Ostapezuk A, Showrońska M, et al. Weekend versus weekday admissions in Polish stroke centres: could admission day affect prognosis in Polish ischaemic stroke patients? Neurol Neurochir Pol 2012;46:15-21.

12 McKinney JS, Deng Y, Kasner SE, et al. Comprehensive stroke centers overcome the weekend versus weekday gap in stroke treatment and mortality. Stroke 2011;42:2403-9. 
13 Crowley RW, Yeoh HK, Stukenborg GJ, et al. Influence of weekend hospital admissions on short-term mortality after intracerebral haemorrhage. Stroke 2009;40:2387-92.

14 Saposnik G, Baibergenova A, Bayer N, et al. Weekends: a dangerous time for having a stroke? Stroke 2007;38:1211-15.

15 Gallerani M, Imberti D, Bossone E, et al. Higher mortality in patients hospitalized for acute aortic rupture or dissection during weekends. J Vasc Surg 2012;55:1247-54.

16 Ricciardi R, Roberts PL, Read TE, et al. Mortality rate after non elective hospital admission. Arch Surg 2011;146:545-51.

17 Bottle A, Middleton S, Kalkman CJ, et al. Global comparators project: international comparison of hospital outcomes using administrative data. Health Serv Res 2013;48:2081-100.

18 Elixhauser A, Steiner C, Harris DR, et al. Comorbidity measures for use with administrative data. Med Care 1998;36:8-27.

19 Altman DG, Bland JM. Interaction revisited: the difference between two estimates; Statistical Notes. BMJ 2003;326:219.

20 Barnett MJ, Kaboli PJ, Sirio CA, et al. Day of the week of intensive care admission and patient outcomes: a multisite regional evaluation. Med Care 2002;40:530-9.

21 Cram P, Hillis SL, Barnett M, et al. Effects of weekend admission and hospital teaching status on in-hospital mortality. Am J Med 2004;117:151-7.

22 Vonlanthen R, Clavien P-A. What factors affect mortality after surgery? Lancet 2012;380:1034-6.

23 Pouw ME, Peelen LM, Moons KG, et al. Including post-discharge mortality in calculation of hospital standardised mortality ratios: retrospective analysis of hospital episode statistics. BMJ 2013;347:f5913.
24 HCUP Home. Healthcare Cost and Utilization Project (HCUP). December 2014. Agency for Healthcare Research and Quality, Rockville, MD. http://www.hcup-us.ahrq.gov/home.jsp

25 Tovim DB, Woodman R, Harrison JE, et al. Measuring and reporting mortality in hospital patients. Australian Institute of Health and Welfare. Cat. no. HSE 69, 2009.

26 Mohammed MA, Sidhu KS, Rudge G, et al. Weekend admission to hospital has a higher risk of death in the elective setting than in the emergency setting: a retrospective database study of National Health Service hospitals in England. BMC Health Serv Res 2012;12:87.

27 Bhonagiri D, Pilcher DV, Bailey MJ. Increased mortality associated with after hours and weekend admission to the intensive care unit: a retrospective analysis. Med J Aust 2011;194:287-92.

28 Zare MM, Itani KM, Schifftner TL, et al. Mortality after non emergent major surgery performed on Friday versus Monday through Wednesday. Ann Surg 2007;246:866-74.

29 Ko DT, Krumholz HM, Wang Y, et al. Regional differences in process of care and outcomes for older acute myocardial infarction patients in the United States and Ontario, Canada. Circulation 2007;115:196-203.

30 Kuijsten HAJM, Brinkman S, Meynaar IA, et al. Hospital mortality is associated with ICU admission time. Intensive Care Med 2010;36:1765-71.

31 Canadian Institute for Health Information. Weekend admissions and in-hospital mortality. Ottawa, ON: CIHI, 2014.

32 Burns EM, Rigby E, Mamidanna R, et al. Systematic review of discharge coding accuracy. J Public Health 2012;34:138-48. 